\title{
DESIGN: CONTRIBUIÇÕES PROJETUAIS E CRIATIVAS À PRÁTICA DA SUSTENTABILIDADE NA CONSTRUÇÃO CIVIL
}

\author{
LEONARDO THOMÉ DE ANDRADE | UERJ \\ LUIZ VIDAL GOMES, Dr. | UERJ \\ PAULO CESAR MACHADO FERROLI , Dr. | UFSC
}

Em nosso mundo contemporâneo identificamos a coexistência de dois paradigmas paradoxais: o paradigma vigente, da lógica capitalista, que vive seu ápice e inicia seu declínio, e o paradigma emergente, da lógica da Sustentabilidade, que vem ganhando consistência no século XXI.

O setor da construção civil, com recorte no canteiro de obras, foi escolhido por ser de baixa sustentabilidade, de grande importância para a qualidade de vida da sociedade, e um campo representativo de profissionais, processos e materiais, onde o designer projetista tem potencial para identificar oportunidades de contribuição e propor mudanças nos modos de projetar e construir que colaborem com o desenvolvimento sustentável e alinhados com o novo paradigma.

A dissertação propõe uma abordagem epistemológica crítica, pois parte da premissa de que os conhecimentos tecnológicos aplicados nos setores produtivos obedecem, em sua grande maioria, a interesses ideológicos e às consequências dessa prática para toda a sociedade. Ela explora a coexistência dos padrões vigentes e em formação, analisando os seus aspectos e buscando soluções para que a sociedade brasileira alcance níveis de qualidade de vida superiores aos atuais. Através da construção de uma perspectiva histórica, será possível detectar formas de interferir efetivamente em processos em curso e no futuro próximo.

A revisão bibliográfica da dissertação incluiu conceitos advindos de múltiplas esferas, que contribuem para a estruturação do novo paradigma ao longo do século $X X$ e se alinham com o conceito de sustentabilidade. Das Ciências Naturais, por exemplo, a Teoria dos Sistemas de Bertalanffy, das décadas de 50 e 60 , coloca que os sistemas são abertos, análogos a organismos vivos e capazes de se equilibrarem interna e externamente. Das Ciências Econômicas vale destacar a obra do economista e filósofo francês Serge Latouche, que distingue desenvolvimento de crescimento econômico e faz críticas contundentes ao sistema capitalista. O também economista Celso Furtado e o designer Aloisio Magalhães, na década de 70 ressaltam a importância da valorização da nossa diversidade cultural para a criação de um modelo de desenvolvimento genuinamente brasileiro. Das Ciências Sociais, o designer e arquiteto Victor Papanek, estudioso de antropologia, critica o consumismo e valoriza a participação do designer em projetos com cunho social, principalmente em países subdesenvolvidos e em desenvolvimento. Do universo corporativo é relevante a contribuição do consultor corporativo John Elkington que cunhou a expressão Triple bottom line, comumente traduzida para o português como tripé da sustentabilidade. A este modelo vários autores propõem adaptações, inclusões, revisões, dentre as quais uma das mais aceitas é a inclusão da dimensão cultural, utilizada nessa dissertação. Para a reflexão sobre a complexidade do cenário que se configura estar de acordo com a relevância do debate, é preciso compreender ainda conceitos como: justiça social, impacto ambiental, diversidade cultural e viabilidade financeira.

A revisão de literatura incluiu também a pesquisa de leis, normas e certificações relacionadas a sustentabilidade na construção civil, das quais podemos destacar a lei CONAMA, a Norma NBR 15.575 e as certificações verdes, que fez parte da pesquisa com entrevistas semiestruturadas com consultores e auditores.

O foco da dissertação foram metodologias projetuais aplicadas e aplicáveis à sustentabilidade e em desenvolvimento, nas áreas de Engenharia, Arquitetura e Desenho Projetual.

Em Engenharia, nas visitas técnicas realizadas em canteiros de obras foram detectadas dissonâncias entre projetação e execução que comprometem durabilidade, manutebilidade e consequentemente a sustentabilidade da edificação. Os Manuais de Práticas encontrados, com 
descritivos dos procedimentos sem ilustrações e com péssima comunicação visual com o público-alvo destinado, são tratados como mera formalidade e seus procedimentos muitas vezes não são cumpridos.

Em Arquitetura foram analisadas três metodologias projetuais aplicáveis à Sustentabilidade: Lean Construction, derivada do Sistema Toyota de Produção , criado na década de 50, com o objetivo de reduzir custos, eliminar erros de concepção de projeto, integrar equipe e aumentar a produtividade; Building Information Modelling (BIM), metodologia de modelagem de projeto que utiliza plataformas digitais para inserir dados e informações e compartilhá-las com as equipes de projeto com o objetivo de ensaiar desempenhos e dar suporte às tomadas de decisão; e Open Building, que propõe um sistema construtivo que possibilite a adaptação do espaço interno da construção maximizando a versatilidade e minimizando os desperdícios de materiais construtivos.

Em Desenho Projetual foi realizada uma ampla pesquisa de autores, metodologias propostas, análises sobre metodologias existentes e propostas de contribuição. Dentre tantos, destacamos:

- Bonsiepe e Löbach, da Escola Funcionalista, com proposições focadas em Projeto de Produto no contexto industrial, porém conceitualmente aplicáveis a projetos da construção civil, especificamente em canteiros de obras;

- Baxter, também focado em Projeto de Produto, que valoriza o trabalho interdisciplinar entre design e marketing;

- Bomfim que afirma que "O Design é uma práxis essencialmente interdisciplinar." E, embora não tenha proposto método, coloca conceitos importantes para um novo modus operandi: fala em usabilidade, mapas mentais, clínica de produtos, para atender às necessidades do usuário;

- Manzini e Vezzoli, que dão duas contribuições relevantes para a concepção de Metodologias aplicáveis à sustentabilidade: LCD (Projeto de Ciclo de Vida), que propõe projetar produtos por processos com o mínimo de impacto ambiental em todas as etapas e LCA (Avaliação do Ciclo de Vida), que faz o levantamento dos inputs e outputs significativos no sistema. Esse método é utilizado em algumas Normas ISO.

As metodologias inovadoras também foram analisadas, com destaque para a impressão 3D, já presente no mercado mundial e viável financeiramente em alguns nichos e em franca expansão para outros nichos.

As pesquisas e coletas de dados foram feitas em três frentes:

- entrevistas a consultores auditores de certificações verdes;

- visitas a canteiros de obras feitas em Florianópolis, e
- pesquisa de madeiras plásticas existentes no mercado.

O momento de construção do novo paradigma é uma grande oportunidade de valorização profissional do designer. Para que esses processos sejam catalisados e se sinergizem devemos nos valer do legado das metodologias e instrumentalizar o designer em formação de competências e valores profissionais alinhados com a sustentabilidade e designers profissionais da capacidade de aprender, desaprender e reaprender. Essa transformação gera uma nova gestalt da profissão e contribui para que o design seja entendido como umprocesso e não um evento. Diante desse cenário, a definição de Design Industrial de 2015 do International Council of Societies of Industrial Design é a mais adequada ao paradigma sustentável, que define o designer como ator estratégico dos processos de inovação, que coloca o ser humano no centro do processo, enxerga problemas como oportunidades, fala em qualidade de vida, transdisciplinaridade, criatividade.

O Estudo das metodologias, métodos, processos de Design nos permite identificar a sua evolução conceitual, abrangência e aspirações. Ao longo do século XX a complexificação das demandas gerou a necessidade de inclusão de competências projetuais da profissão. Atualmente presenciamos o Design em pleno processo de reposicionamento e ressignificação. O Design contemporâneo projeta holisticamente incorporando teoria e prática, tecnologia e inovação. Profissões como Administração, Arquitetura, Artes, Marketing, Publicidade, Engenharia demandam o campo profissional para o design. Cada vez mais frequentemente são requeridas ao designer competências de disciplinas como Psicologia, Ecologia, Filosofia, Economia, Antropologia, Tecnologia, dentre outras, que, aplicadas ao projeto, serão de grande contribuição. As demandas projetuais determinam o repertório metodológico a ser utilizado, os métodos e processos aplicáveis.

De acordo com Leonard Bruce Archer "O problema do Design resulta de uma necessidade." Partindo então dessa afirmativa elabora-se a questão: "O Problema Projetual da Sustentabilidade na Construção Civil resulta de quais necessidades?"

Para isso compõem-se o cenário da sustentabilidade, com seus pilares: social, ambiental, financeiro e cultural, os atores: sujeito criador (designer, arquiteto, engenheiro), sujeito produtor (empresário, fabricante, distribuidor) e cliente (usuário, consumidor, comprador) e o enredo de conceitos e valores: ética, humanismo, transdisciplinaridade, sustentabilidade.

A Contribuição do Design para a Sustentabilidade na Construção Civil com recorte no canteiro de obras é, portanto, riquíssima e multifacetada. Na habilidade Design 
de Produto a pesquisa de materiais com demandas de sustentabilização em diversas etapas de seus ciclos de vida, como madeira, gesso e concreto armado e de processos construtivos, passíveis de inovações incrementais e disruptivas pontuais ou globais. A Comunicação Visual, por sua vez, pode contribuir na criação de sistemas de sinalização interna da obra, com pictogramas por exemplo e manuais de operações legíveis, modulares, em cartilhas ou libretos. $\mathrm{Na}$ área de Design de Interação a contribuição relevante é o desenvolvimento e implementação de utilização de aplicativo para mestres de obra e engenheiros de atualizações online de realizações e sequenciamento de tarefas, cumprimento de prazos, utilização de materiais, demanda de mão-de-obra.

Essa dissertação foi desenvolvida em um cenário de crises nacionais e transformação mundial. As pesquisas realizadas revelam a complexidade do tema, a multiplicidade de faces das questões de aprofundamento urgente, terreno fértil para profissionais criativos em equipes multidisciplinares inovarem projetivamente colocando em prática teorias que vem sendo construídas ao longo das últimas décadas e que alicerçam o novo paradigma. A ampliação do campo do design, com a reavaliação de valores profissionais construídos academicamente e reconstruídos mercadologicamente, o uso estratégico da criatividade, inerente à profissão fundamentam a ressignificação do profissional projetivo designer do século XXI e o alinham ao novo paradigma.

O paradigma da Sustentabilidade em concepção requer habilidades de múltiplos profissionais empenhados em construir um futuro melhor para as próximas gerações. O cenário da indústria da construção civil é especialmente fértil para pesquisa, desenvolvimento e inovação para a Sustentabilidade. Que o trabalho do designer dentro de equipes transdisciplinares seja de sustentabilizar projetos. 
